\title{
STRESSORS AND STRESS MANAGEMENT STRATEGIES ADOPTED BY STUDENT NURSES IN AMBROSE ALLI UNIVERSITY NIGERIA
}

\section{${ }^{* 1}$ Brotobor, D., ${ }^{2}$ Edeawe, O.I., ${ }^{3}$ Owoeye, I.D., ${ }^{4}$ Bankole, S.O., ${ }^{5}$ Brotobor, O. \& ${ }^{6}$ Famuyide, O.K.}

${ }^{1 \& 6}$ Department of Nursing Science, Ambrose Alli University, Ekpoma, Edo State, Nigeria.

${ }^{2}$ Department of Clinical Science, Ambrose Alli University, Ekpoma, Edo State, Nigeria.

${ }^{3}$ Department of Nursing Science, Afe Babalola University, Ado Ekiti, Nigeria.

${ }^{4}$ Department of Nursing, Irrua Specialist Teaching Hospital, Irrua, Edo State, Nigeria.

${ }^{5}$ Department of Surgery, Delta State University Teaching Hospital, Oghara, Delta State, Nigeria

*Corresponding Author Email: deliverancebrotobor@gmail.com

\begin{abstract}
Stress reduces productivity and increase pressure that can influence student nurses learning and academic performance negatively. The stressors faced by student nurses are enormous and their impact is huge. It is important to enhance positive and adaptive behavior in student nurses as it might affect their coping method in practice. Aim: To examine the different stressors and stress management strategies adopted by student nurses of the Department of Nursing Science, at the Ambrose Alli University, Ekpoma, Edo State, Nigeria. Methodology: This study used a cross-sectional survey, using structured questionnaires. Using the census approach, the 314 undergraduate students of the department of nursing, at the Ambrose Alli University, Ekpoma were used. Results: Out of 314 of the respondents, 301 (95.9\%) agreed that academic work was their main source of stress. When faced with stress, majority of the respondents (73.6\%) reported to always become religious; they pray for guidance and strength. Some also reported that they always rest when they experience stressful situations (70.4\%), $45.5 \%$ reported to always seek support from healthcare workers, friends, family and their lecturers, while 51.6\% respondents claimed they occasionally go for recreational activities. Conclusion: There should be a continuous effort to counsel student nurses; create some diversional therapies and revision of the academic workload. These are essential in creating an enabling and motivating environment for learning and practice.
\end{abstract}

Keywords: management, nurses, stress, stressors strategies, student

LICENSE: This work by Open Journals Nigeria is licensed and published under the Creative Commons Attribution License 4.0 International License, which permits unrestricted use, distribution, and reproduction in any medium, provided this article is duly cited.

COPYRIGHT: The Author(s) completely retain the copyright of this published article.

OPEN ACCESS: The Author(s) approves that this article remains permanently online in the open access (OA) model.

QA: This Article is published in line with "COPE (Committee on Publication Ethics) and PIE (Publication Integrity \& Ethics)". 


\section{INTRODUCTION}

Stressful events are part of day-to-day living. These stressors could be internal or external events that create the potential for physiologic, emotional, cognitive or behavioral changes in an individual (Smith, 2017; Abdulghami, Alkanhd, Mohmoud, Ponnamperum \& Alfaris, 2011). These stressful challenges encountered by student nurses may include increase academic workload, insecurity about clinical competence and interpersonal relationship with patients, interaction with dying patients and interpersonal conflict with other students, assignment submission and deadlines, poor transition from family to school environment and poor social life ( $\mathrm{Ng}$, Haslam, Haslam \& Cruwys, 2018; Yasmin, Hussain, Parveen \& Gilani, 2018; Wu, Tseng, Tseng, Chen, Pai \& Yen, 2021). In addition, Chen (2019) reported that inter-personal and environmental sources of stress were the most common; finding new friends, new responsibilities, unfamiliar environment and working with unknown people. The situations that seem to be stressful to the student nurses may cause some negative changes in their psychosocial lives, physical and mental wellbeing on the long term (Ingram, Maciejewski \& Hand, 2020).

Students experiencing stress may be irritable, show lack of concentration, decreased academic performance, poor interpersonal relations, insomnia and absenteeism (Qutub et al., 2018). Chapman, Wilson, Wilson and Dunkley (2020) revealed that stress could result into exhaustion, depersonalization and decreased personal achievements. Stressful events could make student nurses experience deterioration in academic performance which may result to elimination from the nursing programme and shortage of nurses in clinical career (Moustaka \& Constantinidis, 2019).

Furthermore, studies found that one third of student nurses experience severe stress that might induce mental health problems such as depression and anxiety (Chernomas \& Shapiro, 2013; Zeng, Wang, Xie, Hu \& Reinhardt, 2019). Since there are diverse types of stressors and consequences experienced by student nurses, the ability to cope with stress is essential for them to succeed. Adopting appropriate management strategies is very important for counteracting the negative effect of stress. When stress is properly managed, adaptation takes place and promotes psychological wellbeing and social functioning (Azuzu, 2009; Soares \& Olivieria, 2013).

Stress management could be behavioral or psychosocial approaches that people employ to tolerate or reduce or minimize stressful events (Regehr, Glancy \& Pitts, 2013). It could also be problem solving or emotional focused coping strategies (Al-Gamal, Alhosain \& Alusunaye, 2018). Study showed that students at lower-level experience more stress than those in higher level (Misra \& McKeen, 2010). Though, there are no specific guidelines for coping strategies, some strategies are dependent on socio-cultural factors. Different stressor management has been identified to be effective. It is important to find the stress point, reduce the stress through diversion and humor. Martin et al. (2018) suggested therapy such as social activities, art therapy, and involvement of specialized training opportunities including workshops on stressor management. Also, providing support within the academic system may involve group and individual counseling as well as direct access to resources (Al-Gamal, Alhosain \& Alusunaye, 2018).

However, nursing is a lifelong demanding profession. Stress management studies have shown that students can do little to significantly reduce stress which they experience or to which they are exposed (Regehr, Glancy \& Pitts, 2013). Thus, student nurses must be taught how to adapt and prioritize their own care amidst the other demands required of the profession (Jarrad, Hammed, Shawashi \& Mahmoud, 2018). Nonetheless, coping and appraisal are 
affected by internal characteristics such as health, energy, personal belief system commitments, life goals, problem solving skill and health promoting lifestyle (Cooper, Brown, Rees \& Leslie, 2020).

\section{AIM OF THE STUDY}

To examine the different stressors and stress management strategies adopted by student nurses of the Department of Nursing Science, at the Ambrose Alli University, Ekpoma, Edo State, Nigeria.

\section{MATERIAL AND METHODS}

This study utilized a cross-sectional survey design to assess the stress and stress management strategies adopted by student nurses of the Department of Nursing Science, at the Ambrose Alli University, Ekpoma, Edo State, Nigeria. Using the census approach, the 314 undergraduate students of the department of nursing, at the Ambrose Alli University, Ekpoma, were recruited for the study. A structured questionnaire was designed to cover the questions related to the different stressors and stress management strategies adopted by student nurses. After ethical approval was granted by the Health Research Ethics Committee of the University, data collection was done in the different level lecture theatres. At the different lecture theatres, verbal consent was obtained before data collection. All the questionnaires were retrieved. Data collected were analyzed using the Statistical Package for Social Sciences (SPSS) version 22. Data were presented using frequency and percentage.

\section{RESULTS}

Section 1: Sociodemographic Characteristics

Table 1: Sociodemographic Characteristic Data

\begin{tabular}{lll}
\hline Variables & Frequency & Percentage \% \\
\hline Age & & \\
$16-25$ & 212 & 67.5 \\
26-35 & 96 & 30.6 \\
35 and above & 6 & 1.9 \\
Total & $\mathbf{3 1 4}$ & $\mathbf{1 0 0}$ \\
Level of study & & \\
100level & 90 & 28.6 \\
200level & 64 & 20.4 \\
300level & 58 & 18.5 \\
400level & 52 & 16.6 \\
500level & 50 & 15.9 \\
Total & $\mathbf{3 1 4}$ & $\mathbf{1 0 0}$ \\
Gender & & \\
Male & 20 & 6.4 \\
Female & 294 & 93.6 \\
Total & $\mathbf{3 1 4}$ & $\mathbf{1 0 0}$ \\
Religion & & \\
Christianity & 294 & 93.6 \\
Islam & 18 & 5.7 \\
Traditional & 2 & 0.6 \\
Total & $\mathbf{3 1 4}$ & $\mathbf{1 0 0}$ \\
\hline
\end{tabular}


From Table 1, the maximum age range of the respondents was between 16-25 years (67.5\%). Female respondents made up a total of 294 (93.6\%). The maximum number of the respondents were in level 100 (28.6\%), followed by 64 (20.6\%) in level 200, while the lowest number of respondents (15.9\%) were in 500level (final year). On the religious variable, 294 (93.6\%) of the respondents were Christians, 18 (5.7) were Muslims and 2 (0.6) were traditional worshippers.

\section{Section 2: Identification of Stressors}

Table 2 represents the data analyzed on stress identification. Out of 314 of the respondents, $301(95.9 \%)$ agreed that academic work was their main source of stress. Responses such as examination, lack of adequate academic resources and accommodation had the following responses 299 (95.2\%), 293 (93.3\%) and 281 (89.5\%) respectively. Furthermore, some respondents had stress generated from clinical posting frequency and long hours in clinical postings (see table 2).

Table 2: Identification of Stressors $(n=314)$

\begin{tabular}{|c|c|c|c|c|c|c|}
\hline \multirow[b]{2}{*}{ Variables } & \multicolumn{2}{|l|}{ Agreed } & \multicolumn{2}{|l|}{ Disagreed } & \multirow{2}{*}{$\begin{array}{l}\text { No } \\
\text { response } \\
\text { Frequency }\end{array}$} & \multirow[b]{2}{*}{ Percentage \% } \\
\hline & Frequency & $\begin{array}{l}\text { Percentage } \\
\%\end{array}$ & Frequency & Percentage $\%$ & & \\
\hline Academic work & 301 & 95.9 & 12 & 3.8 & 1 & 0.3 \\
\hline Accommodation & 281 & 89.5 & 25 & 7.9 & 8 & 2.5 \\
\hline Examination & 299 & 95.2 & 11 & 3.5 & 4 & 1.3 \\
\hline $\begin{array}{l}\text { Clinical posting } \\
\text { frequency }\end{array}$ & 228 & 72.6 & 79 & 25.2 & 7 & 2.2 \\
\hline $\begin{array}{l}\text { Long hours in } \\
\text { clinical posting }\end{array}$ & 246 & 78.3 & 60 & 19.1 & 8 & 2.5 \\
\hline $\begin{array}{l}\text { Lack of adequate } \\
\text { academic } \\
\text { resources }\end{array}$ & 293 & 93.3 & 17 & 5.4 & 4 & 1.3 \\
\hline
\end{tabular}

Section 3: Coping Strategies for the stress Management

Table 3 shows that majority of the respondents (73.6\%) reported to always become religious as they pray for the guidance and strength. Also, some reported that they always rest when they experience stressful situations (70.4\%), $45.5 \%$ reported to always seek support from healthcare workers, friends, family and their lecturers, while 5.1.6\% respondents claimed they occasionally go for recreational activities. In addition, 89.9\%, 68.2\%, 88.5\% and 92.7\% responded that they never took drugs like sedatives, alcohol, cigarette smoking and hard drugs to cope with stressful situations. 
Table 3: Coping strategies for the stress management $(n=314)$

\begin{tabular}{|c|c|c|c|c|}
\hline Variables & Always & Occasional & Never & No response \\
\hline $\begin{array}{lrr}\text { Seeking } & \text { support } & \text { from } \\
\text { healthcare } & \text { workers, } \\
\text { friends, } & \text { family } & \text { and } \\
\text { lecturers } & & \\
& & \end{array}$ & $143(45.5 \%)$ & $114(36.3 \%)$ & $38(12.1 \%)$ & $19(6.1 \%)$ \\
\hline $\begin{array}{l}\text { Becoming religious and } \\
\text { praying for guidance and } \\
\text { strength }\end{array}$ & $231(73.6 \%)$ & $62(19.7 \%)$ & $20(6.4 \%)$ & $1(0.3 \%)$ \\
\hline Recreation activities/ sport & $56(17.8 \%)$ & $162(51.6 \%)$ & $80(25.5 \%)$ & $16(5.1 \%)$ \\
\hline Rest & & & & \\
\hline $\begin{array}{l}\text { Taking drugs such as } \\
\text { sedatives }\end{array}$ & $\begin{array}{l}221(70.4 \%) \\
5(1.6 \%)\end{array}$ & $26(8.3 \%)$ & $\begin{array}{l}12(3.8 \%) \\
282(89.8 \%)\end{array}$ & $\begin{array}{l}1(0.3 \%) \\
1(0.3 \%)\end{array}$ \\
\hline Taking alcohol & $15(4.8 \%)$ & $76(24.2 \%)$ & $214(68.2 \%)$ & $9(2.9 \%)$ \\
\hline $\begin{array}{l}\text { Hard drugs (Indian hemps, } \\
\text { cocaine) }\end{array}$ & $3(0.9 \%)$ & $22(7.0 \%)$ & $278(88.5 \%)$ & $11(3.5 \%)$ \\
\hline
\end{tabular}

\section{DISCUSSION}

This study examined stressors and stress management strategies adopted by student nurses of the department of Nursing Science, at the Ambrose Alli University, Ekpoma, Edo State, Nigeria. From the demographic analysis, majority of the respondents were aged 16-25 years (67.5\%) and followed by 26-35 (30.6\%). Study claimed that high levels of stress were not associated with students' age (Al-Qahtani \& Alsubaie, 2020). This study included every student of the department. From the findings, there were more students in the lower level than the higher level. A previous study opined that those in second and third year are less likely to show high stress level compared to those in the fourth and final year (Al-Qahtani \& Alsubaie, 2020). In agreement, another study revealed that higher level students have stress more than lower-level students due to their difficulty in juggling responsibilities between study, work, and family, and the nature of studying for external final examinations (He, Turnbull, Kirhbaum, Phillips \& Klainin-Yobas, 2018). On the other hand, Misra and McKeen (2010) claimed that students in lower levels are more prone to high stress than those in higher level due to less experience in the academic environment. Hence, students should be guided to reduce their stress levels, as this can enhance their quality of life and study experience.

This study found that majority of the respondents mentioned academic work, examination, lack of adequate academic resources and accommodation as major stress producing situations. Al-Gamal, Alhosain and Alusunaye (2018) reported academic workload as source of stress that was most common among their cohort of students. In affirmation, findings from studies revealed that examination, intense amount of work, finding academic work difficulty and financial problem were the most important source of stress (Evans and Kelly, 2004; Ganesan, Talwar, 
Norsiah \& Oon, 2018; Vaul, 2021). Besides, the nature of clinical posting and long hours in clinical posting were identified as stressors. It should be noted that clinical practices are significant part of student nursing educational programme. From previous research, majority of the student nurses felt 'happy and proud' being on the clinical posting but noted various anxiety producing factors during the clinical work (Damodaran \& Kandasamy, 2013). Therefore, Damodaran and Kandasamy (2013) recommended that the department of Nursing can establish and maintain a cordial, working relationship with the nursing service department; special attention provided to students experiencing severe stress, anxiety and adjustment problems.

Reflecting on the demographic data, this study found that majority of the students are in lower level. This could imply stress increasing the level of dropout, hence, lesser number getting to final year. From the finding of this study, majority of the respondents (73.6\%) reported to be religious, praying for guidance and strength to cope with stress. Felicilda-Reynaldo, et al (2019) found that frequent religious activities lead to better physical and environment domains for coping among student nurses. In addition, Madian, Abdelaziz and Ahmed (2019) revealed that in their study, most frequently used coping mechanism to stress was religious coping and acceptance. Record has it that student nurses experience a high level of stress and it is important that academic authorities recognize the coping strategies of students experiencing stress for effective coping (Rafati, Nouhi, Sabzevari \& Dehghan-Nayeri, 2017). Having examined the different stress management strategies adopted by the respondents of this study, it could be said that they used a variety of strategies; which are both adaptive and maladaptive. This could have been influenced due to their level of fear and the different option to enhance coping.

This study also found that some respondents sought for support from friends, family, healthcare workers and lecturers for guidance. A group of respondents also reported to be involved in recreational activities while others used rest to cope with stress. This is in line with a previous study where many students coped with stress by using their family problem solving strategies, some tried to personally figure out how to deal with their problem (66.4\%), improve themselves (64.5\%), try keeping up friendship (54.4\%), spiritual strategies (65.8\%), relaxing strategies (52.5\%) and talking with a teacher or counselor (Sayedfatemi, Tafreshi \& Hagani, 2007). Furthermore, receiving emotional and spiritual support from family, friends and the university lecturers can have a good mental health from stressful events; such social support gives students a perception of being loved, cared for and feeling of respect (Sodeify \& Tabrizi, 2020). Moreover, Park and Kim (2018) discovered in their study that their research subjects adopted creation of selfcoping strategies in physically active manner; creating coping strategies in a non-physical but positive form; and relying on religious belief and spiritual power to cope with stressful events. More so, Wunsch, Kasten and Fuchs (2017) found that physical activity and exercise in during examination period can help combat negative effects of stress on health-related outcomes.

Majority of the respondents claimed to have never taken drugs like sedatives (89.8\%), alcohol (68.2\%), cigarette smoking $(88.5 \%)$ and hard drugs $(92.7 \%)$ to relieve stress. Though, a few of the respondents reported to have used hard drugs, cigarette smoking and use of sedative either always or occasionally (refer to Table 3). In harmony with this study, a previous study with similar high score revealed that most of their cohorts reported to have avoided smoking (93.7\%) and drinking of beer or wine (92.9\%) when in stressful situations (Sayedfatemi, Tafreshi \& Hagani, 2007). Students who might have lacked resilience in coping may resolve to the use of maladaptive behavior such as 
use of substances. Nursing profession is stressful. It is important to enhance positive and adaptive behavior in student nurses as it might affect their coping method in practice. A previous study among staff nurses revealed that nurses use cigarettes smoking, sleeping pills, and power drinks to cope with stress (Jarrad, Hammed, Shawashi \& Mahmoud, 2018). Student nurses must be monitored on substance abuse and various relevant authorities should be aware of the substance drive among student nurses and plans developed to solve substance use problem.

\section{CONCLUSION}

Stress in nursing is an endemic problem. Stress reduces productivity and increase pressure that can influence student nurses learning and academic performance negatively. The stressors faced by student nurses are enormous and their impact is huge. Some of the stresses encountered by the student nurses are increased academic work, accommodation stress, examination, and clinical posting. Nonetheless, the students developed strategies like seeking support from

friends, family, health workers and lecturers. They also used religion coping, recreational activities and observing rest to relieve the effect of stress. Therefore, there should be a continuous effort to counsel student nurses; create some diversional therapies and revision of the academic workload. These are essential in creating an enabling and motivating environment for learning and practice. 


\section{REFERENCES}

Abdulghami, H.M., Alkanhd, A.A., Mohmoud, E.S., Ponnamperum, G.G. \& Alfaris, E.A. (2011). Stress and Its Effects on Medical Students: A Cross Sectional Study at a College of Medicine in Saudi Arabia. Journal of Health Population Nutr, 29(5), 516-522.

Al-Gamal, E., Alhosain, A. \& Alusunaye, K. (2018). Stress and Coping Strategies among Saudi Nursing Students during Clinical Education. Perceptive in Psychiatric Care, 54(2), 198-205.

Al-Qahani, M.F. \& Alsubaie, R. A.S. (2020). Investigating Stress and Sources of Stress among Female Health Profession Student in a Saudi University. Journal of Multidisciplinary Healthcare.13:477-484.

Azuzu, C.R. (2019). Choking under Pressure of Self Consciousness and Paradoxical Effects of Skillful Performance. Journal of Personality and Social Psychology, 46(3), 610-620.

Chen, M. (2019). The Impact of Expatriates' Cross-Cultural Adjustment on Work Stress and Job Involvement in the High-tech Industry. Frontiers in Psychology, 10:22-28.

Chernomas, W.M. \& Shapiro, C. (2013). Stress, Depression and Anxiety among Undergraduate Nursing Students. International Journal of Nursing Education Scholarship, 10(1), 255-266.

Cooper, A. L., Brown, J.A., Rees C.S. \& Leslie, G.D. (2020). Nurse Resilience: A Concept Analysis. International Journal of Mental Health Nursing,29(4), 553-575.

Damodaran, D.K. \& Kandasemy, M. (2013). Clinical Environment: Experiences of Undergraduate student Nurses. International Journal of Advance Nursing Management. 1(1), 25-30.

Evans, W. \& Kelly, B. (2004). Pre-registration Diploma Student Nurses Stress and Coping Measures. Nurse Education Today, 24(6) 473-482.

Felicilda-Raynaldo, R.F.D., Cruz, J.P., Papathanscious, I.V., Shaji, J.C.H., Kamau, S.M., Adams, K.A. \& Valdez, G.F.D. (2019). Quality of Life and the Predictive Roles of Religiosity Spiritual Coping among Students: A Multi-Country Study. Journal of Religion and Health,58(5), 1573-1591.

Ganesan, Y., Talwar, P., Norsiah, F. \& Oon, Y.B. (2018). A Study on Stress Level and Coping Strategies among Undergraduate Students. Journal of Cognitive Science Human Development, 3(2), 37-47.

He, F.X., Turnbull, B., Kirshbaum, M.N., Phillips, B. \& Klainin Y. (2018). Assessing Stress, Protective Factors and Psychological Wellbeing among Undergraduate Nursing Students. Nurse Education Today, 68:4-12.

Ingram, J., Maciejewski, G. \& Hand, C.J. (2020). Changes in Diet, Sleep and Physical Activity are Associated with Differences in Negative Mood during COVID-19 Lockdown. Frontiers in Psychology, 11:23-28.

Jarrad, R., Hammad, S., Shawashi, T. \& Mohmoud, N (2018). Compassion Fatigue and Substance Use among Nurses. Annals of General Psychiatry,17(1),1-8. 
Martin, L., Oepen, R., Bauer, K., Nottensteiner, A., Mergheim, K., Gruber, H. \& Koch, S.C. (2018). Creative Arts Interventions for Stress Management and Prevention- A Systematic Review. Behavioral Sciences.8(28), 1-18.

Misra, R. \& McKeen, M. (2010). College Students Academic Stress and Its Relation to their Anxiety, Time Management and Leisure Satisfaction. American Journal of Health Studies. 16: 41-51.

Moustaka, A. \& Constantinidis, T. (2019). Sources and Effects of Work-related Stress in Nursing. Health Science Journal,4(4), 210-216

Ng, W.K N., Haslam,mS.A., Haslam, C. and Cruwys, T. (2018). How can you make Friends if you don’t know who you are? A Qualitative Examination of International Students' Experience informed by the Social Identity Model of Identity Change. Journal of Community \& Applied Social Psychology, 28(3), 169-187.

Qutub, MF., Azahrani, A.A., Bafail, M.A, Alomari, A.S., Abuznadah, W.T., Alsaywid, B.S., \& Munshi, M.F. (2018) Asenteesim among Saudi Medical Students. The Egyptian Journal of Hospital Medicine, 70(8), 1248-1253.

Rafati, F., Nouhi, E., Sazevoir, S. \& Dehgham-Nayeri, N. (2017). Coping Strategies of Nursing Students for Dealing with Stress in Clinical Setting: A Qualitative Study. Electronic Physician, 9(12), 6120-6128.

Regehr, C., Glancy, D. \& Pitts, A. (2013). Interventions to Reduce Stress in University Students: A Review and Metaanalysis. Journal of Affective Disorder,148(1), 1-11.

Smith, S. (2017). Mindfulness-Based Stress Reduction: an Intervention to enhance the Effectiveness of Nurses' Coping with Work-Related Stress. International Journal of Nursing Knowledge, 25(2), 119-130.

Soares, K. Oliveria, B. (2013). Health Psychology: Bio: Psychological Interactions. John Wileys \& Sons: New York.

Vaul, M.A. (2021). Impact of Stress on Student's Academic Performance in Zanzibar's Higher Learning Institutions. Asian Journal of Education and Social Studies, 16(3), 18-25.

Wu, P., Tseng, S., Tseng, Y., Chen, L., Pai, H. \& Yen, W. (2021). Job Stress and Occupational Burnout among Clinical Nursing Teachers: A Cross Sectional Study. Journal of Professional Nursing, 37(5), 907-915.

Yasmin, S., Hussain, M., Parveen, S. \& Gilani, S.A. (2018). Coping Strategies of Nursing Student against Academic and Clinical Stress at Public Sector Labore. International Journal of Social Sciences and Management,5(3), 209-218.

Zeng, Y., Wang, G., Xie, C., Hu, X. \& Reinhardt, J.D. (2019). Prevalence and Correlates of depression, Anxiety and symptoms of stress in Vocational College Nursing Students from Sichuan, China: A Cross-sectional Study. Psychology, Health \& Medicine, 24(7), 798-811. 